\title{
Resveratrol Attenuates Microglial Activation via SIRT1-SOCS1 Pathway
}

\author{
Shuping Zhang, ${ }^{1}$ Lu Gao, ${ }^{2}$ Xiuying Liu, ${ }^{3}$ Tao Lu, ${ }^{1}$ Chuangbo Xie, ${ }^{4}$ and Ji Jia ${ }^{4}$ \\ ${ }^{1}$ Department of Dermatology, The First Affiliated Hospital, Shantou University Medical College, Shantou 515041, China \\ ${ }^{2}$ Department of Neurosurgery, Xian Children's Hospital, Xian 710003, China \\ ${ }^{3}$ Guangzhou University of Chinese Medicine, Guangzhou 510045, China \\ ${ }^{4}$ Department of Anesthesiology, Guangzhou General Hospital of Guangzhou Military Command, Guangzhou 510010, China
}

Correspondence should be addressed to Ji Jia; jiaji1981@126.com

Received 7 March 2017; Accepted 12 June 2017; Published 11 July 2017

Academic Editor: Janelle Wheat

Copyright (C) 2017 Shuping Zhang et al. This is an open access article distributed under the Creative Commons Attribution License, which permits unrestricted use, distribution, and reproduction in any medium, provided the original work is properly cited.

\begin{abstract}
Microglial activation is involved in a variety of neurological disorders, and overactivated microglial cells can secrete large amount of proinflammatory factors and induce neuron death. Therefore, reducing microglial activation is believed to be useful in treating the disorders. In this study, we used $10 \mathrm{ng} / \mathrm{ml}$ lipopolysaccharide plus $10 \mathrm{U} / \mathrm{ml}$ interferon $\gamma$ (LPS/IFN $\gamma$ ) to induce N9 microglial activation and explored resveratrol- (RSV-) induced effects on microglial activation and the underlying mechanism. We found that LPS/IFN $\gamma$ exposure for $24 \mathrm{~h}$ increased inducible nitric oxide synthase (iNOS) and nuclear factor $\kappa \mathrm{B}$ (NF- $\kappa \mathrm{B}$ ) p65 subunit expressions in the cells and enhanced tumor necrosis factor $\alpha$ (TNF- $\alpha$ ) and interleukin $1 \beta$ (IL-1 $\beta$ ) releases from the cells. RSV of $25 \mu \mathrm{M}$ reduced the iNOS and NF- $\kappa \mathrm{B}$ p65 subunit expressions and the proinflammatory factors' releases; the knockdown of silent information regulator factor 2-related enzyme 1 (SIRT1) or suppressor of cytokine signaling 1 (SOCS1) by using the small interfering RNA, however, significantly abolished the RSV-induced effects on iNOS and NF- $\kappa$ B p65 subunit expressions and the proinflammatory factors' releases. These findings showed that microglial SIRT1-SOCS1 pathway may mediate the RSV-induced inhibition of microglial activation in the LPS/IFN $\gamma$-treated N9 microglia.
\end{abstract}

\section{Introduction}

Neuroinflammation is involved in a variety of neurological disorders, including brain ischemia, brain trauma, and neurodegenerative diseases [1-3]. As a vital immunocyte in the central nervous system (CNS), microglia can be activated in the neurological disorders above. Overactivation of microglia can enhance the inflammation in the CNS by secreting proinflammatory cytokines, leading to neuron death and neurological dysfunction ultimately [4, 5]. Therefore, inhibiting microglial activation is regarded as an effective therapy in treating the CNS diseases. At present, two main kinds of anti-inflammatory drugs are widely used clinically, steroidal anti-inflammatory drugs and nonsteroidal anti-inflammatory drugs (NSAIDs). Long-term use of steroidal anti-inflammatory drugs, such as dexamethasone and prednisone, may induce immune dysfunction, infection, and lipid metabolism disorders $[6,7]$. In contrast, administration of NSAIDs, such as aspirin, ibuprofen, and indometacin, may cause gastric ulcer, coagulation disorders, and renal dysfunction [8-10]. Given these reasons, searching for effective anti-inflammatory drugs with fewer and more mild side effects is a vital issue in treating inflammatory disorders.

Resveratrol is a bioactive substance rich in grape and Asian herbal medicine Polygonum cuspidatum [11, 12]. Some latest investigations showed that resveratrol can reduce microglial activation in brain ischemia and neurodegenerative disorders $[13,14]$. And some studies showed that resveratrol can reduce brain injury in brain ischemia and Alzheimer's disease $(\mathrm{AD})$ by increasing silent information regulator factor 2 -related enzyme 1 (SIRT1) $[15,16]$. However, the accurate mechanism of resveratrol in reducing microglial activation is still elusive. Suppressor of cytokine signaling 1 (SOCS1) is a protein, expressed in lymphocytes and microglial cells [17, 18]. Overexpression of SOCS1 protein decreases the activation 
of macrophage in the peripheral tissue and microglia in the CNS $[19,20]$.

In this study, we used lipopolysaccharide (LPS) plus interferon gamma (IFN $\gamma$ ), two proinflammatory substances, to activate N9 microglial cells [21], and took resveratrol to decrease the activation of the cells. We hypothesized that resveratrol can decrease the activation of N9 microglial cells exposed to LPS plus IFN $\gamma$, and microglial SIRT1-SOCS1 pathway may mediate the anti-inflammatory process of resveratrol.

\section{Materials and Methods}

2.1. Materials. N9 cell, a mouse microglial cell line, was obtained from the Fourth Military Medical University, China. The N9 microglial cells are very similar to the primary cultured microglial cells in producing cytokines and reacting to stimulus. The IMDM cell culture medium, fetal bovine serum (FBS), LPS (Escherichia coli, O55:B5), IFN $\gamma$, methylthiazol tetrazolium (MTT), and resveratrol were purchased from Sigma-Aldrich (USA). The SIRT1-siRNA, SOCS1-siRNA, and scrambled- (SC-) siRNA were purchased from Santa Cruz Biotechnology (USA). Antibodies against iNOS, SIRT1, SOCS1, and NF- $\kappa$ B p 65 subunit were purchased from the Abcam (Cambridge, UK). Antibodies against $\beta$-actin and GAPDH and Cy3-labeled secondary antibody were obtained from the Beijing Comwin Biotech Co., Ltd. (China).

2.2. Cell Culture and Treatments. The N9 microglial cells were cultured in the IMDM medium, containing 5\% FBS, $100 \mathrm{U} / \mathrm{ml}$ penicillin, $100 \mu \mathrm{g} / \mathrm{ml}$ streptomycin, and $2 \mathrm{mM}$ glutamine. The air in the cell incubator was humidified and contained 5\% $\mathrm{CO}_{2}$ and $95 \%$ air at $37^{\circ} \mathrm{C}$. The medium was changed every 3 days. The stock cells were passaged 2-3 times per week with a split ratio of $1: 4$, and the cells were used within 8 weeks.

To find a suitable resveratrol (RSV) treatment concentration, the microglial cells were divided into five groups, including the LPS/IFN $\gamma$ group, cells cultured in the medium containing $10 \mathrm{ng} / \mathrm{ml} \mathrm{LPS}$ and $10 \mathrm{U} / \mathrm{ml} \mathrm{IFN} \gamma$, and four RSV treatment groups, cells cultured in the medium containing different concentrations of $\operatorname{RSV}(5,10,25$, and $50 \mu \mathrm{M})$, $10 \mathrm{ng} / \mathrm{ml} \mathrm{LPS}$, and $10 \mathrm{U} / \mathrm{ml}$ IFN $\gamma$. After $24 \mathrm{~h}$ incubation, western blot was used to evaluate iNOS protein expression in the cells. Then, to explore the role of SIRT1 in RSVinduced effects on microglial activation, we used SIRT1siRNA to knock down the SIRT1 protein expression. The cells were divided into three groups: control: cells were cultured in the serum-free medium for $6 \mathrm{~h}$ and then exposed to normal medium for $6 \mathrm{~h}$; SIRT1-siRNA: cells were cultured in the serum-free medium containing 90 pmol SIRT1-siRNA for $6 \mathrm{~h}$; scrambled- (SC-) siRNA: cells were cultured in the serum-free medium containing $90 \mathrm{pmol}$ SC-siRNA for $6 \mathrm{~h}$ and then exposed to normal medium for $6 \mathrm{~h}$, and western blot was used to assess SIRT1 expression level. Then, the cells were divided into five groups: control group, LPS/IFN $\gamma$ treatment group, $25 \mu \mathrm{M}$ resveratrol (RSV) + LPS/IFN $\gamma$ group, SIRT1-siRNA + RSV + LPS/IFN $\gamma$ group, and SC-siRNA $+\mathrm{RSV}+\mathrm{LPS} / \mathrm{IFN} \gamma$ group. After the treatments, western blot was performed to assess the iNOS and SOCS1 protein expressions, enzyme-linked immunosorbent assay (ELISA) was used to measure TNF- $\alpha$ and IL- $1 \beta$ concentrations in the medium, and immunocytochemistry was taken to observe iNOS expression. Furthermore, in order to explore the role of SOCS1 in resveratrol-induced effects, we took SOCS1siRNA to silence SOCS1 protein expression. The cells were divided into three groups: control: cells were cultured in the serum-free medium for $6 \mathrm{~h}$ and then exposed to normal medium for $6 \mathrm{~h}$; SOCS1-siRNA: cells were cultured in the serum-free medium containing 60 pmol SOCS1-siRNA for $6 \mathrm{~h}$; SC-siRNA: cells were cultured in the serum-free medium containing 60 pmol SC-siRNA for $6 \mathrm{~h}$ and then exposed to normal medium for $6 \mathrm{~h}$, and western blot was used to determine the SOCS1 expression. The cells were then divided into five groups: control group, LPS/IFN $\gamma$ treatment group, $\mathrm{RSV}+\mathrm{LPS} / \mathrm{IFN} \gamma$ treatment group, SOCS1-siRNA + RSV + LPS/IFN $\gamma$ group, and SC-siRNA + RSV + LPS/IFN $\gamma$ group. After the treatments, western blot was performed to assess the iNOS and NF- $\kappa$ B p 65 subunit expressions and ELISA was used to measure TNF- $\alpha$ and IL- $1 \beta$ concentrations in the medium.

2.3. Cell Viability Assay. The cells were seeded in a 96-well cell culture plate at a density of $1 \times 10^{4}$ cells/well. After the treatments, $20 \mu \mathrm{l}$ of MTT solution $(5 \mathrm{mg} / \mathrm{ml})$ was added to each well. After $4 \mathrm{~h}$ incubation at $37^{\circ} \mathrm{C}$, the medium in the 96-well plate was removed, and $150 \mu$ l of dimethyl sulfoxide (DMSO) was added to each well to dissolve the formazan product. Then, the plate was shaken for $10 \mathrm{~min}$ to make all the formazan dissolve completely. The absorbance was then detected at $490 \mathrm{~nm}$ wavelength by using a spectrophotometer (TECAN, CH). The values were expressed as percentage of the control group.

2.4. Western Blot Analysis. The microglial cells were seeded in 6 -well cell culture plates at a density of $2 \times 10^{6}$ cells/well. After the treatments, the cells were collected. Then, the total protein was evaluated by using the Bradford method. The western blot analysis was performed as described previously [22]. The following primary antibodies against iNOS (1:1000), SIRT1 $(1: 1000)$, SOCS1 $(1: 1000)$, NF- $\kappa \mathrm{B}$ p65 subunit $(1: 1000)$, GAPDH $(1: 1000)$, and $\beta$-actin $(1: 1000)$ were used in this study. Chemiluminescence technique was taken to detect the antigens. Image analysis was performed by using computerized analysis software from Bio-Rad Laboratories (USA).

2.5. ELISA. The microglial cells were plated in 24 -well cell culture plates at a density of $1 \times 10^{5}$ cells/well, and, after the treatments, TNF- $\alpha$ and IL- $1 \beta$ concentrations in the supernatants were measured by using the corresponding Reagent Kit (Nanjing Jiancheng Bioengineering Institute, China). Briefly, after the treatments, the supernatants from the cell culture medium were collected by centrifugation at $14000 \mathrm{rpm}$ for $5 \mathrm{~min}$ at room temperature. Then the levels of TNF- $\alpha$ and IL- $1 \beta$ were tested according to the manufacturer's instructions.

2.6. Immunocytochemistry. The microglial cells were seeded in confocal microscope specific cell culture plates at a density 


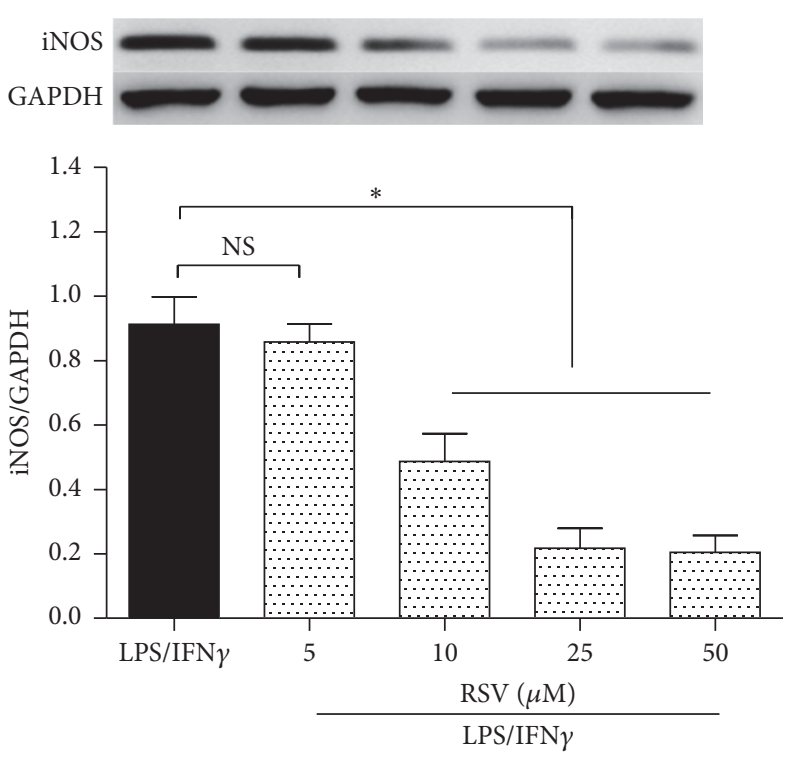

(a)

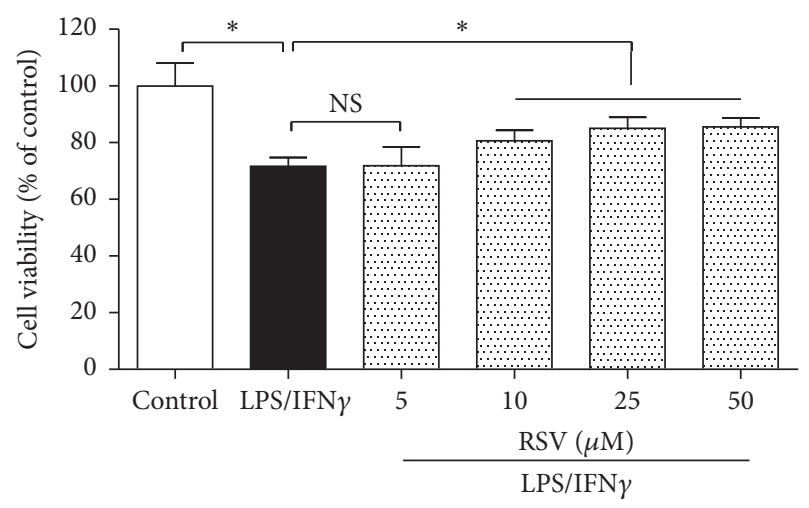

(b)

FIGURE 1: Resveratrol reduced iNOS expression and restored cell viability in the microglial cells exposed to LPS plus IFN $\gamma$. (a) The N9 microglial cells were divided into five groups, including $10 \mathrm{ng} / \mathrm{ml} \mathrm{LPS} \mathrm{plus} 10 \mathrm{U} / \mathrm{ml}$ IFN $\gamma$ (LPS/IFN $\gamma$ ) exposure group, and four concentrations of resveratrol (RSV) treatment groups $(5 \mu \mathrm{M}, 10 \mu \mathrm{M}, 25 \mu \mathrm{M}$, and $50 \mu \mathrm{M})$. After $24 \mathrm{~h}$ incubation, western blot analysis was taken to evaluate the iNOS protein expression in the cells $(n=4)$. (b) The cells were divided into six groups, including control, LPS/IFN $\gamma$, and four concentrations of resveratrol (RSV) treatment groups $(5 \mu \mathrm{M}, 10 \mu \mathrm{M}, 25 \mu \mathrm{M}$, and $50 \mu \mathrm{M})$. After $24 \mathrm{~h}$ incubation, MTT assay was taken to evaluate the cell viability $(n=8)$. Results are expressed as means \pm SD. ${ }^{*} P<0.05$; NS: no significance.

of $5 \times 10^{4}$ cells/well. After the treatments, the cells were fixed with $4 \%$ paraformaldehyde for $30 \mathrm{~min}$ at room temperature. Then the cells were washed three times with phosphate buffered saline (PBS). Next, the cells were exposed to $5 \mathrm{mg} / \mathrm{ml}$ bovine serum albumin for $30 \mathrm{~min}$, followed by three times of washing with PBS. The cells were incubated in anti-iNOS primary antibody (1:50 in dilution) overnight at $4^{\circ} \mathrm{C}$. After the incubation, the cells were washed with PBS three times, 5 min per time. Then the cells were incubated in Cy3-labeled secondary antibody ( $1: 100$ in dilution); after $1 \mathrm{~h}$ incubation at room temperature, $200 \mu \mathrm{l}$ of DAPI solution was added to each cell culture plate. After $10 \mathrm{~min}$ incubation in dark at room temperature, the plates were washed with PBS three times, 5 min per time. Then the cells were observed by using the confocal microscope (Olympus, Japan); photos were taken randomly.

2.7. siRNA Interfering. To downregulate SIRT1 or SOCS1 protein expression in the N9 microglial cells, the cells were treated with 90 pmol SIRT1-siRNA or 60 pmol SOCS1-siRNA by using the Lipofectamine reagent (Invitrogen, USA) in serum-free medium, according to the manufacturer's instructions. The cells were incubated for $6 \mathrm{~h}$ and recovered for an additional $6 \mathrm{~h}$ before the exposures of the drugs. The SCsiRNA was taken as the negative control.

2.8. Statistical Analysis. In this study, SPSS 13.0 for Windows (SPSS Inc., USA) was taken to conduct the statistical analysis. All the values of this study were expressed with means \pm standard deviation (SD). The results of the groups were compared by one-way ANOVA, followed by Tukey's Multiple Comparison Test. $P<0.05$ indicates statistical significance.

\section{Results}

3.1. Resveratrol Reduced iNOS Expression and Restored Cell Viability in Microglial Cells Exposed to LPS/IFN $\gamma$. To activate N9 microglial cells and mimic neuroinflammation, we used $10 \mathrm{ng} / \mathrm{ml} \mathrm{LPS}$ plus $10 \mathrm{U} / \mathrm{ml} \mathrm{IFN} \gamma$ and took western blot analysis and MTT assay to evaluate iNOS protein expression and cell viability level, respectively. A high iNOS expression level indicates microglial activation. The N9 microglial cells were divided into five groups (Figure 1(a)): LPS/IFN $\gamma$ exposure group and $5 \mu \mathrm{M}, 10 \mu \mathrm{M}, 25 \mu \mathrm{M}$, and $50 \mu \mathrm{M}$ of resveratrol treatment groups. After $24 \mathrm{~h}$ treatment, compared with the LPS/IFN $\gamma$ exposure group, $10 \mu \mathrm{M}, 25 \mu \mathrm{M}$, and $50 \mu \mathrm{M}$ of resveratrol reduced the microglial iNOS expression significantly $(P<0.05)$. Then, the cells were divided into six groups, control group and the five groups as above (Figure 1(b)). After $24 \mathrm{~h}$ treatment, LPS/IFN $\gamma$ exposure reduced the cell viability significantly $(P<0.05)$, and $10 \mu \mathrm{M}, 25 \mu \mathrm{M}$, and $50 \mu \mathrm{M}$ of resveratrol restored the cells viability markedly $(P<0.05)$. These findings showed that resveratrol exposure can reduce microglial activation and injury in the presence of LPS/IFN $\gamma$. And $25 \mu \mathrm{M}$ of resveratrol was used in the subsequent experiments to explore the anti-inflammatory effects of the drug.

3.2. SIRT1-siRNA Reversed Resveratrol-Induced Inhibition of Microglial Activation Significantly. To explore the role of 

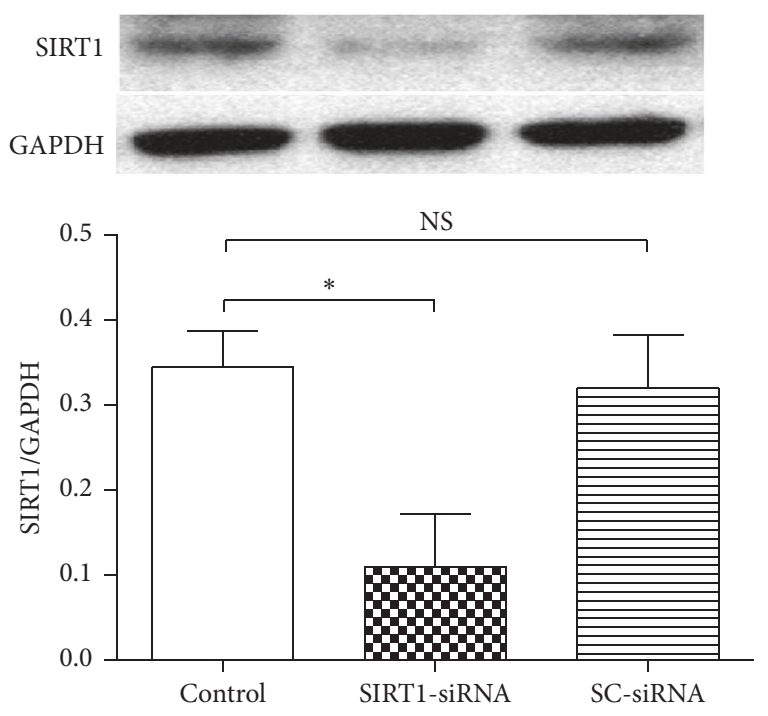

(a)

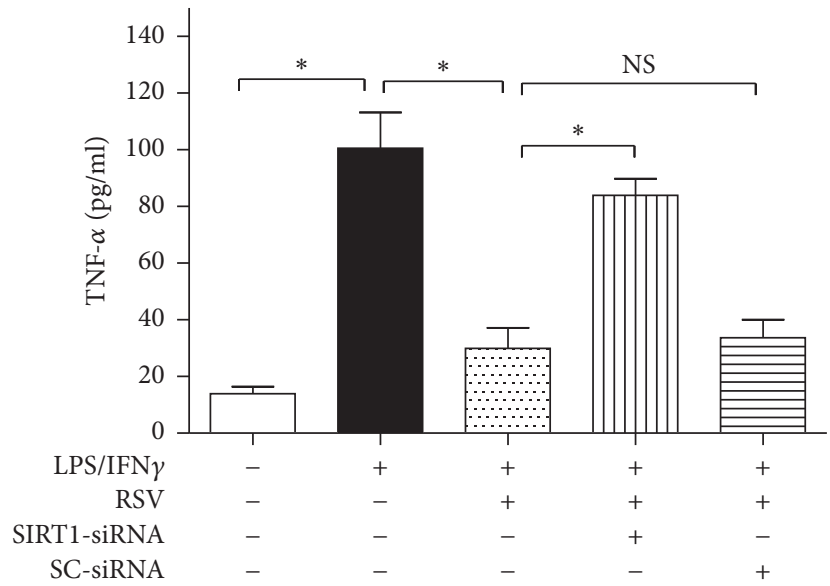

(c)

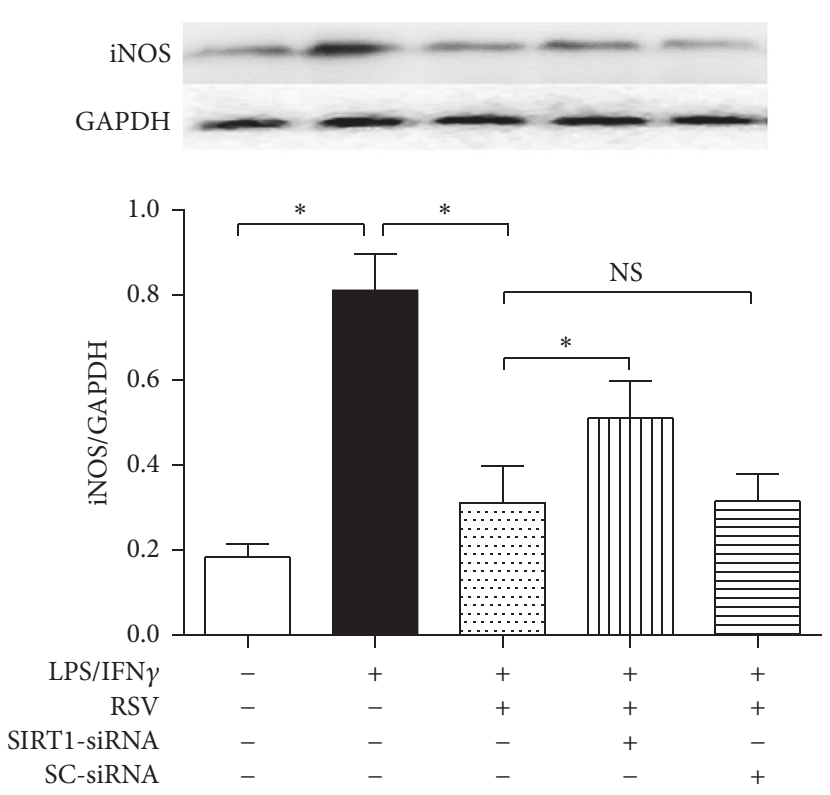

(b)

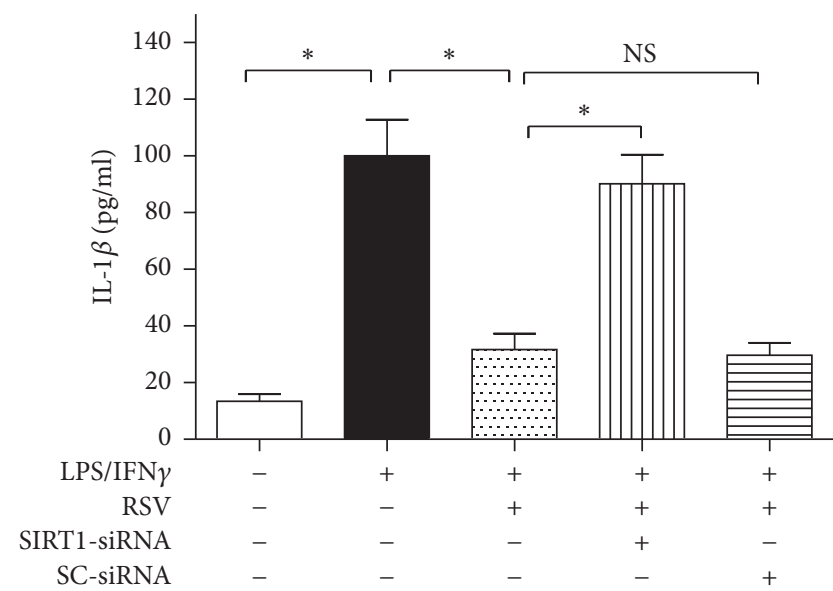

(d)

FIGURE 2: SIRT1-siRNA reversed resveratrol- (RSV-) induced effects on iNOS expression and proinflammatory factors' releases. (a) SIRT1siRNA was effective in downregulating SIRT1 protein expression. The cells were divided into three groups as shown in the figure. After $6 \mathrm{~h}$ incubation, the SIRT1 protein expression was assessed by western blot analysis $(n=4)$. (b) Microglial iNOS protein expression $(n=4)$. (c) TNF- $\alpha$ concentration in the supernatants $(n=8)$. (d) IL-1 $\beta$ concentration in the supernatants $(n=8)$. The cells were divided into five groups and treated with different drugs as shown in the figure. After $24 \mathrm{~h}$ incubation, western blot and ELISA kits were used to assess iNOS expression and proinflammatory factors' releases, respectively. Results are expressed as means $\pm \mathrm{SD} .{ }^{*} P<0.05$; NS: no significance.

SIRT1 in resveratrol-induced effects on microglial activation, we used SIRT1-siRNA. We found that SIRT1-siRNA downregulated SIRT1 protein expression in N9 microglial cells markedly $(P<0.05)$, but the scrambled siRNA (SC-siRNA) did not (Figure 2(a)). Then we explored the role of SIRT1 in resveratrol-induced effects on iNOS expression (Figures 2 (b) and 3). Compared with the cells exposed to $10 \mathrm{ng} / \mathrm{ml}$ LPS plus $10 \mathrm{U} / \mathrm{ml} \mathrm{IFN} \gamma, 25 \mu \mathrm{M}$ of resveratrol reduced iNOS protein expression obviously $(P<0.05)$; the effect, however, was significantly reversed by SIRT1-siRNA. The SC-siRNA did not cause significant effect on iNOS expression, compared with the resveratrol treatment group.
We also assessed the concentrations of TNF- $\alpha$ and IL$1 \beta$, two proinflammatory factors, in the supernatants of the cell culture medium (Figures 2(c)-2(d)). Compared with the cells cultured in the drug-free medium, LPS/IFN $\gamma$ exposure for $24 \mathrm{~h}$ increased the TNF- $\alpha$ and IL- $1 \beta$ concentrations $(P<$ 0.05 ), and $25 \mu \mathrm{M}$ resveratrol significantly reduced the two cytokines' levels $(P<0.05)$; the SIRT1-siRNA, not the SCsiRNA, however, partially abolished the resveratrol-induced effects on TNF- $\alpha$ and IL-1 $\beta$ levels $(P<0.05)$. These findings above showed that SIRT1 may mediate resveratrol-induced inhibition of microglial activation in the N9 microglial cells exposed to LPS/IFN $\gamma$. 
DAPI

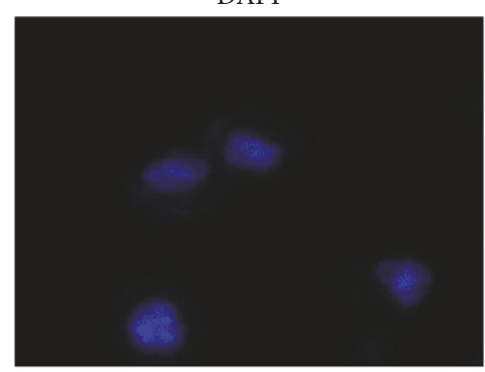

LPS/IFN $\gamma$

$\mathrm{RSV}+$ $\mathrm{LPS} / \mathrm{IFN} \gamma$
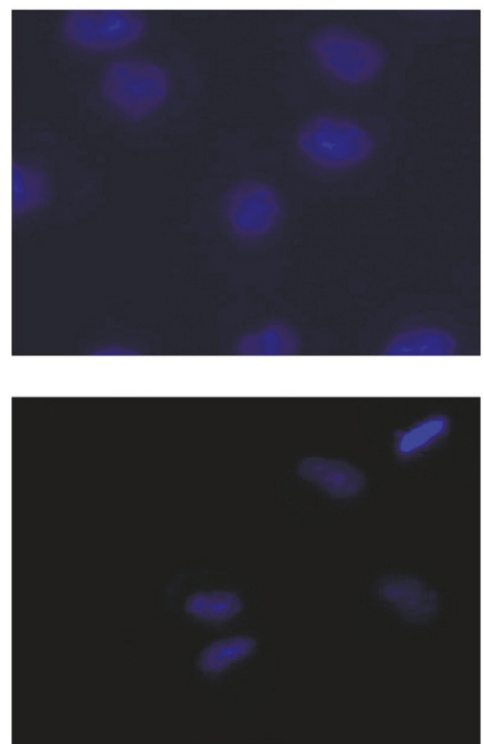

SIRT1-siRNA +

$\mathrm{RSV}+$ $\mathrm{LPS} / \mathrm{IFN} \gamma$
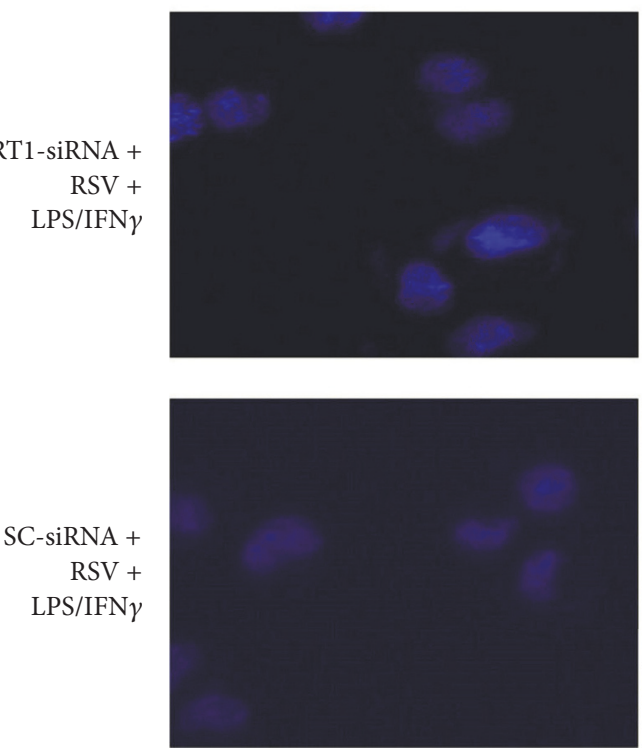

iNOS
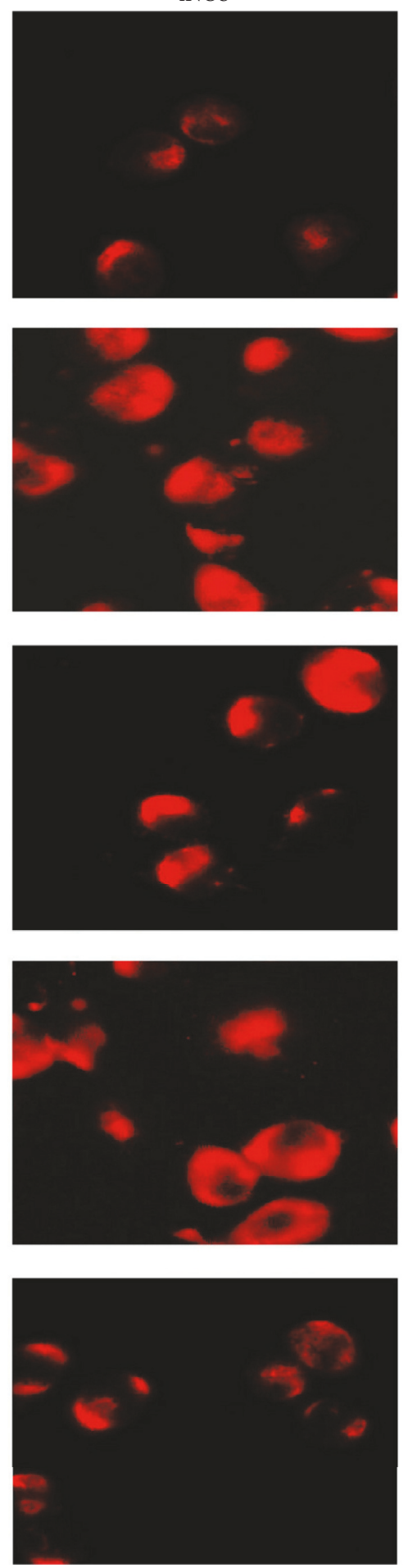

Merge
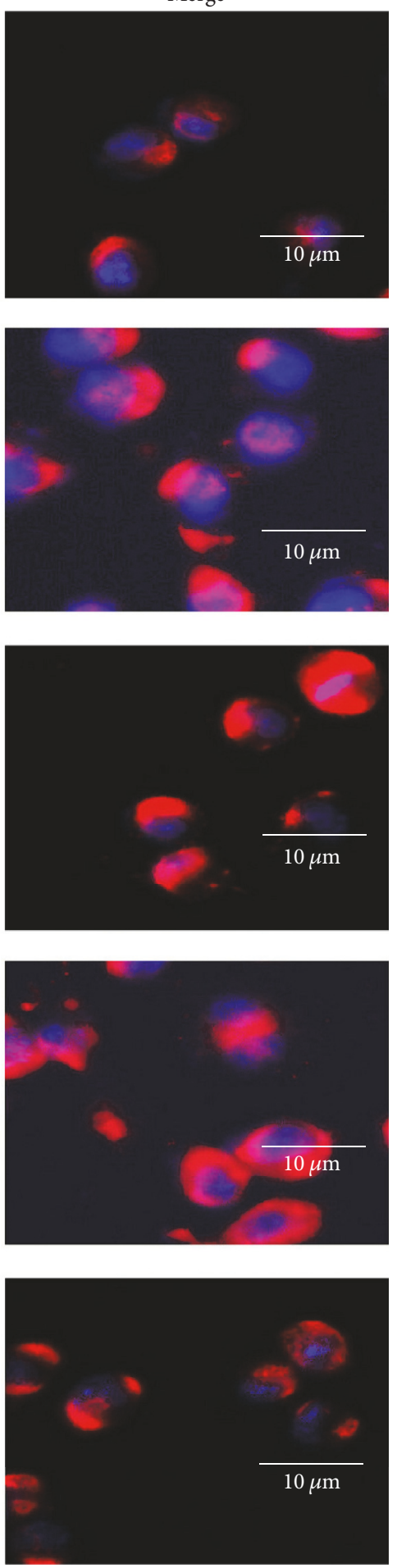

FIGURE 3: SIRT1-siRNA reversed resveratrol- (RSV-) induced effects on iNOS expression. The cells were divided into five groups and treated with different drugs as shown in the figure. After $24 \mathrm{~h}$ incubation, immunocytochemistry was used to observe the iNOS expression (red) in microglial cells, and the nuclei (blue) were counterstained with DAPI staining solution. Bar $=10 \mu \mathrm{m}$. 


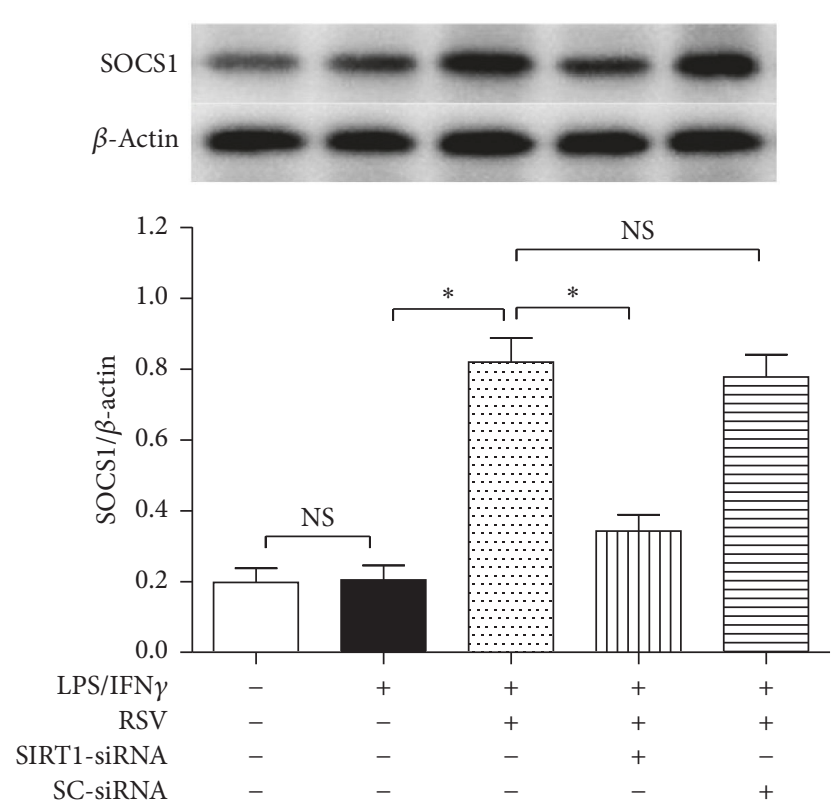

FIGURE 4: SIRT1-siRNA reversed resveratrol- (RSV-) induced effects on SOCS1 expression. The cells were divided into five groups and treated with different drugs as shown in the figure. After $24 \mathrm{~h}$ incubation, western blot was used to evaluate the SOCS1 protein expression in microglial cells $(n=4)$. Results are expressed as means $\pm \mathrm{SD} .{ }^{*} P<0.05$; NS: no significance.

3.3. SIRT1-siRNA Reversed Resveratrol-Induced Effects on SOCS1 Protein Expression in Microglial Cells. To observe the interaction between SOCS1 and SIRT1 proteins, we used western blot to evaluate the SOCS1 protein expression in the presence of SIRT1-siRNA and resveratrol (Figure 4). Compared with the cells exposed to $10 \mathrm{ng} / \mathrm{ml}$ LPS plus $10 \mathrm{U} / \mathrm{ml}$ IFN $\gamma$ alone, $25 \mu \mathrm{M}$ resveratrol increased the SOCS1 expression level significantly $(P<0.05)$; however, the SIRT1siRNA, not the SC-siRNA, abolished the upregulation of SOCS1 protein expression caused by resveratrol obviously $(P<0.05)$.

\subsection{SOCS1-siRNA Reversed Resveratrol-Induced Inhibition} of Microglial Activation. To observe the role of SOCS1 in resveratrol-induced inhibition of microglial activation, we took SOCS1-siRNA to knock down the SOCS1 protein expression. In this experiment (Figure 5(a)), the SOCS1-siRNA reduced the SOCS1 protein expression significantly $(P<$ $0.05)$. Then, by using western blot analysis, we measured the iNOS protein expression (Figure 5(b)). Compared with the cells cultured in drug-free medium, $10 \mathrm{ng} / \mathrm{ml}$ LPS plus $10 \mathrm{U} / \mathrm{ml}$ IFN $\gamma$ exposure for $24 \mathrm{~h}$ upregulated the iNOS protein expression in the N9 microglial cells, and coadministration of $25 \mu \mathrm{M}$ resveratrol reduced the iNOS expression markedly in the presence of LPS/IFN $\gamma$; SOCS1-siRNA, not SC-siRNA, however, significantly reversed the resveratrolinduced reduction of iNOS expression $(P<0.05)$.

Similarly, compared with the cells treated with LPS/IFN $\gamma$, $25 \mu \mathrm{M}$ resveratrol decreased the TNF- $\alpha$ and IL- $1 \beta$ concentrations in the supernatants of the medium $(P<0.05)$, but the SOCS1-siRNA significantly reversed the resveratrolinduced effects on the levels of the two cytokines $(P<$ 0.05 , Figures $5(\mathrm{c})-5(\mathrm{~d}))$, and the SC-siRNA did not cause significant influence on the levels of the two cytokines in the supernatants of the medium $(P>0.05)$.

3.5. SOCS1-siRNA Reversed Resveratrol-Induced Reduction of NF- $\kappa B$ p 65 Subunit Expression in the Microglial Cells. NF- $\kappa \mathrm{B}$ family consists of at least five members, including p65 (RelA), RelB, c-Rel, p50/105 (NF- $\kappa \mathrm{B} 1$ ), and p52/100 (NF- $\kappa \mathrm{B} 2)$. NF- $\kappa \mathrm{B}$ p65 subunit can translocate from cytoplasm to the nucleus and bind inflammation-associated genes. Therefore, a high expression of $\mathrm{NF}-\kappa \mathrm{B}$ p 65 subunit indicates an enhanced inflammation and activation degree in microglial cells [23]. In this study, by using western blot (Figure 6), compared with the cells cultured in drug-free medium, we found that $10 \mathrm{ng} / \mathrm{ml}$ LPS plus $10 \mathrm{U} / \mathrm{ml}$ IFN $\gamma$ exposure for $24 \mathrm{~h}$ increased the NF- $\kappa \mathrm{B}$ p65 subunit expression $(P<0.05)$, and $25 \mu \mathrm{M}$ resveratrol reduced the NF- $\kappa \mathrm{B}$ p65 subunit expression obviously; however, the SOCS1-siRNA partially abolished the resveratrol-induced effect on NF- $\kappa \mathrm{B}$ p 65 subunit expression. These findings above showed that the SOCS1 protein may be involved in resveratrol-induced inhibition of microglial activation.

\section{Discussion}

In this study, we demonstrated that $10 \mathrm{ng} / \mathrm{ml}$ LPS plus $10 \mathrm{U} / \mathrm{ml}$ IFN $\gamma$ exposure for $24 \mathrm{~h}$ increased the protein expressions of iNOS and NF- $\kappa \mathrm{B}$ p65 subunit in the N9 microglial cells and enhanced TNF- $\alpha$ and IL- $1 \beta$ concentrations in the supernatants of the medium, and coadministration of $25 \mu \mathrm{M}$ resveratrol decreased iNOS and NF- $\kappa \mathrm{B}$ p65 subunit protein expressions and reduced the two cytokines' levels. SIRT1-siRNA or SOCS1-siRNA, not the SC-siRNA, however, significantly reversed the resveratrol-induced effects above. These findings indicated that resveratrol attenuates microglial activation induced by LPS plus IFN $\gamma$, and microglial SIRT1SOCS1 pathway may mediate the resveratrol-induced antiinflammatory effects.

Resveratrol was first isolated from the roots of white hellebore and was named by Dr. Michio Takaoka in 1940 [24]. In 1963, resveratrol was isolated from Polygonum cuspidatum, a traditional Chinese and Japanese medicine [25]. At present, resveratrol has been found in skin and seeds of over 70 plants, including grape, berries, grains, tea, and peanuts $[26,27]$. In recent years, a large number of studies were performed to investigate the potential medical applications of resveratrol, including antitumor, antiinflammation, and antioxidation applications and preventing cardiovascular disorders [28-30]. As red wine is rich in resveratrol, this is believed to be the essential factor in the French Paradox [31], a term used frequently to summarize the epidemiological observation that the French have a very low incidence of coronary heart disease despite having a diet rich in saturated fats. In addition, some latest investigations showed that resveratrol induces neuroprotections; the exact mechanism, however, is still elusive. As many studies indicated that resveratrol is a potent agonist for SIRT1, 

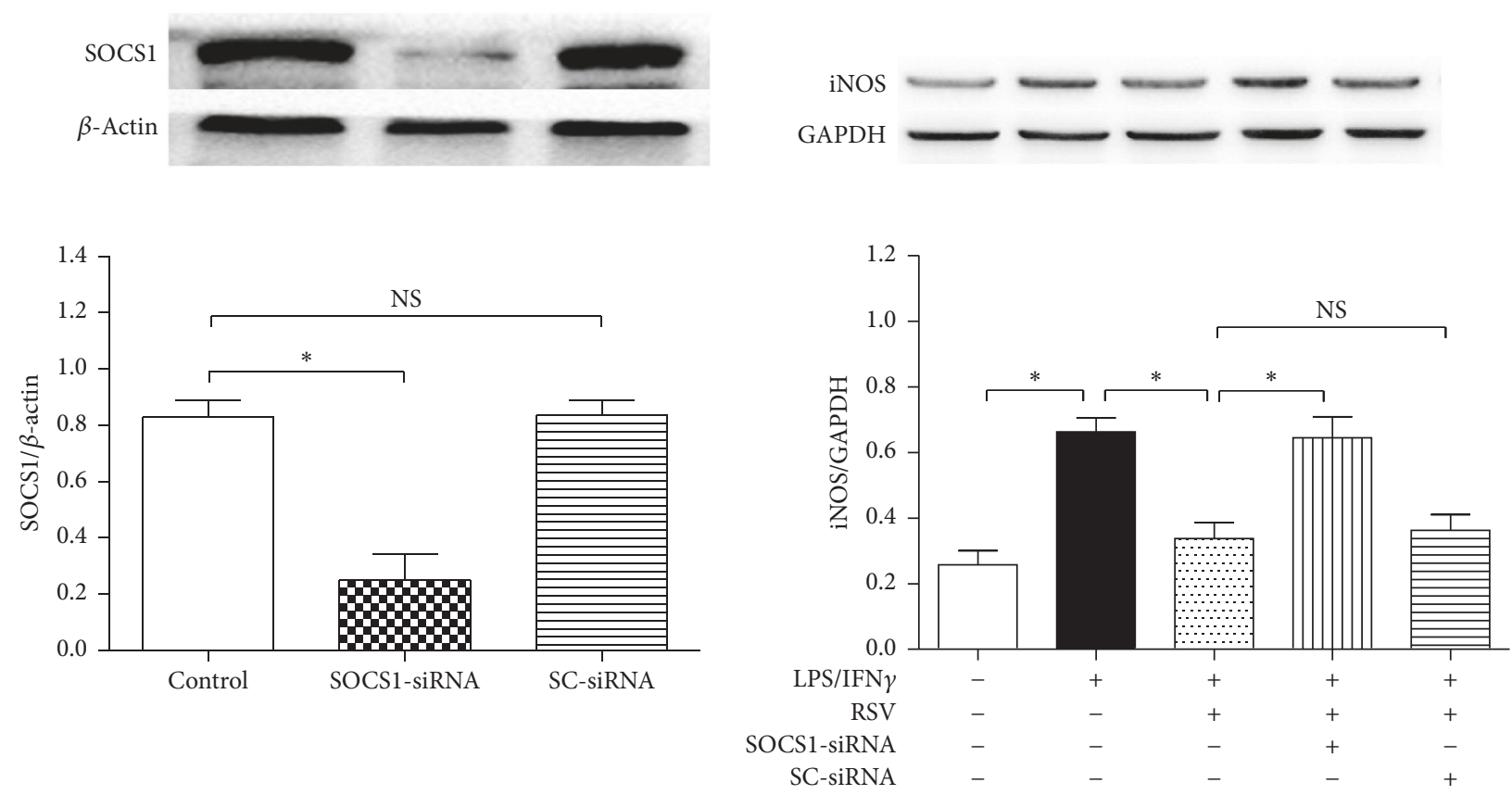

(a)

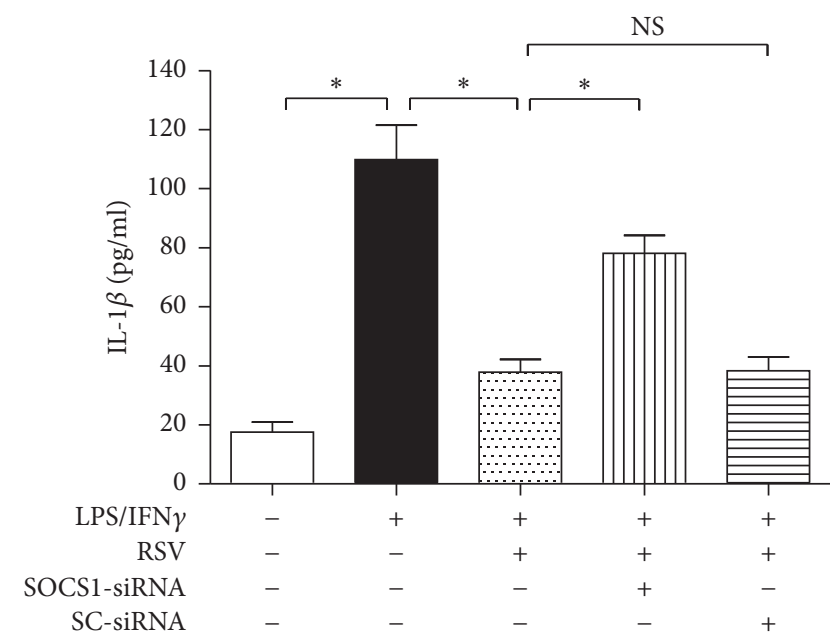

(c)

(d)

FIGURE 5: SOCS1-siRNA reversed resveratrol- (RSV-) induced effects on iNOS expression and proinflammatory factors' releases. (a) SOCS1siRNA was effective in reducing SOCS1 protein expression in N9 microglial cells. The N9 microglial cells were divided into three groups as shown in the figure. After $6 \mathrm{~h}$ incubation, the SOCS1 protein expression was assessed by western blot analysis $(n=4)$. (b) Microglial iNOS protein expression $(n=4)$. (c) TNF- $\alpha$ concentration in the supernatants $(n=8)$. (d) IL- $1 \beta$ concentration in the supernatants $(n=8)$. The cells were divided into five groups and treated with different drugs as shown in the figure. After $24 \mathrm{~h}$ incubation, western blot and ELISA kits were used to assess iNOS expression and proinflammatory factors' releases, respectively. Results are expressed as means \pm SD. ${ }^{*} P<0.05$; NS: no significance.

and SIRT1 upregulation induces neuroprotective and antiinflammatory effects $[15,16]$; therefore, we investigated the role of SIRT1 in resveratrol-induced effects in microglial cells exposed to LPS plus IFN $\gamma$. We found that LPS plus IFN $\gamma$ increased iNOS expression and proinflammatory cytokines' levels in the cell culture medium and resveratrol reduced the iNOS and the cytokines' levels, indicating that LPS/IFN $\gamma$ activated microglial cells and resveratrol caused inhibition of the microglial activation. As the overexpression of SOCS1 protein induces anti-inflammatory effects in microglia and macrophages, and SIRT1 overexpression leads to the methylation of SOCS1 protein [32]; therefore, we also observed the role of SOCS1 in this study. Interestingly, we found that resveratrol exposure increased the SOCS1 protein expression and SIRT1-siRNA partially abolished the SOCS1 protein expression in microglial cells; this result revealed that the SOCS1 protein might be involved in the resveratrol-induced anti-inflammation in the current study. Then we investigated 


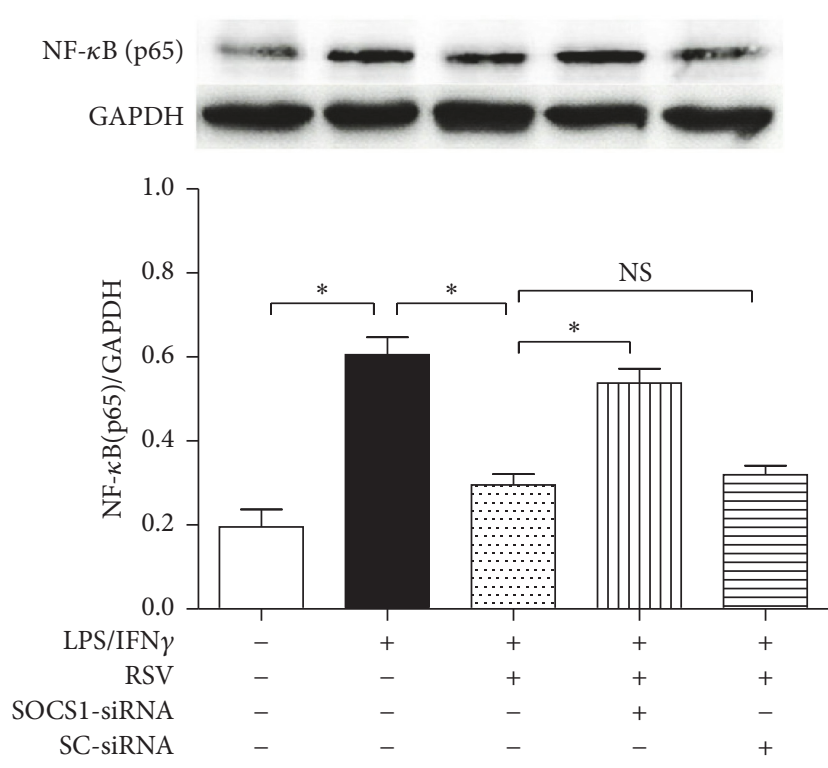

FIGURE 6: SOCS1-siRNA reversed resveratrol- (RSV-) induced effects on NF- $\kappa \mathrm{B}$ p65 subunit expression. The cells were divided into five groups and treated with the drugs as shown in the figure. After $24 \mathrm{~h}$ incubation, western blot was used to assess the protein expression of NF- $\kappa \mathrm{B}$ p65 subunit $(n=4)$. Results are expressed as means \pm SD. ${ }^{*} P<0.05$; NS: no significance.

whether the SOCS1 protein mediates the resveratrol-induced effects. Similarly, the SOCS1-siRNA significantly reversed the resveratrol-induced effects on microglial activation and NF$\kappa \mathrm{B}$ p65 subunit expression, indicating that the SOCS1 protein may mediate the resveratrol-induced anti-inflammation in LPS/IFN $\gamma$-treated microglial cells. In fact, the SOCS protein family consists of at least eight proteins, including SOCS1-7 and cytokine-inducible SH2 protein (CIS) [33-35]. All the SOCS proteins share a central SRC-homology 2 (SH2) domain, a variable $\mathrm{N}$-terminal region containing an extended $\mathrm{SH} 2$ subdomain and a conserved SOCS box at the C-terminus [36]. However, there are closer structures in pairs among the SOCS proteins family: SOCS1 and SOCS3, SOCS4 and SOCS5, SOCS6 and SOCS7, and SOCS2 and CIS. Being different from other SOCS proteins, SOCS1 and SOCS3 are expressed in microglial cells, and some latest studies showed that SOCS1 overexpression can reduce microglial activation by shifting microglial M1 state to M2 state [36]. M1 state of microglial can enhance the secretion of proinflammatory cytokines from the cells, which is believed to be harmful. In contrast, microglia of M2 state can release anti-inflammatory cytokines and neurotrophic factors, including IL-10, glial cell derived neurotrophic factor (GDNF), and brain derived neurotrophic factor (BDNF); therefore, M2 state is neuroprotective. Although we did not test the biomarkers of microglial M2 state, we infer that resveratrol can inhibit LPS/IFN $\gamma$ induced microglial activation via the SIRT1-SOCS1 pathway and the inhibition of microglial activation may be associated with the modulation of microglial activated states. Similarly, Dragone et al. found that resveratrol exposure decreased LPS-induced murine N13 microglial activation cells by increasing the SOCS1 signaling pathway [37]. Moreover, in a 1-methyl-4-phenyl-1,2,3,6-tetrahydropyridine- (MPTP-) induced Parkinson's disease (PD) mouse model, Lofrumento et al. revealed that resveratrol treatment significantly reduced glial activation and decreased the levels of IL-1 $\beta$, IL-6, and TNF- $\alpha$ in the brain tissue by upregulating the SOCS1 protein expression [38]. Additionally, $\mathrm{Ma}$ et al. reported that resveratrol decreased the immune response of LPSstimulated RAW264.7 macrophages via the SOCS1 pathway [39]. As microglial cells are regarded as the macrophages in the brain, these findings above are in accordance with that of ours to a large extent.

However, there are still some limitations in our investigation; first, in this study, we just observed the microglial activation in a microglial cell line, not in primary cultured microglial cells and in vivo. Therefore, the findings of this study should be verified in vivo and in primary cultured cells. Second, SOCS3 is also expressed in microglial cells; whether SOCS3 is involved in the resveratrol-induced antiinflammatory effects is still under investigation. These questions will be answered in our coming work.

In summary, according to the findings of this investigation, resveratrol attenuates LPS plus IFN $\gamma$-induced microglial activation, and the SIRT1-SOCS1 pathway may mediate the anti-inflammation of resveratrol in the N9 microglial cells.

\section{Conflicts of Interest}

The authors declare that there are no conflicts of interest regarding the publication of this paper.

\section{Authors' Contributions}

Shuping Zhang, Lu Gao, and Xiuying Liu contributed equally to this work.

\section{Acknowledgments}

This work was supported by Science and Technology Program of Guangzhou, China (no. 201707010027).

\section{References}

[1] V. Shukla, A. K. Shakya, M. A. Perez-Pinzon, and K. R. Dave, "Cerebral ischemic damage in diabetes: an inflammatory perspective," Journal of Neuroinflammation, vol. 14, no. 1, 2017.

[2] L. Menzel, L. Kleber, C. Friedrich et al., "Progranulin protects against exaggerated axonal injury and astrogliosis following traumatic brain injury," Glia, vol. 65, no. 2, pp. 278-292, 2017.

[3] L. Carniglia, D. Ramŕrez, D. Durand et al., "Neuropeptides and microglial activation in inflammation, pain, and neurodegenerative diseases," Mediators of Inflammation, vol. 2017, Article ID 5048616, 23 pages, 2017.

[4] K. Ding, H. Wang, J. Xu, X. Lu, L. Zhang, and L. Zhu, "Melatonin reduced microglial activation and alleviated neuroinflammation induced neuron degeneration in experimental traumatic brain injury: possible involvement of mTOR pathway," Neurochemistry International, vol. 76, pp. 23-31, 2014.

[5] D. L. Bhoiwala, I. Koleilat, J. Qian et al., "Overexpression of RCAN1 isoform 4 in mouse neurons leads to a moderate 
behavioral impairment," Neurological Research, vol. 35, no. 1, pp. 79-89, 2013.

[6] E. Seelig, S. Meyer, K. Timper et al., "Metformin prevents metabolic side effects during systemic glucocorticoid treatment," European Journal of Endocrinology, vol. 176, no. 3, pp. 349-358, 2017.

[7] A. Caplan, N. Fett, M. Rosenbach, V. P. Werth, and R. G. Micheletti, "Prevention and management of glucocorticoidinduced side effects: a comprehensive review-Gastrointestinal and endocrinologic side effects," Journal of the American Academy of Dermatology, vol. 76, no. 1, pp. 11-16, 2017.

[8] S. Afroz, T. Ikoma, A. Yagi, K. Kogure, A. Tokumura, and T. Tanaka, "Concentrated phosphatidic acid in cereal brans as potential protective agents against indomethacin-induced stomach ulcer," Journal of Agricultural and Food Chemistry, vol. 64, no. 37, pp. 6950-6957, 2016.

[9] P. F. Fogarty, M. E. Mancuso, R. Kasthuri et al., "Presentation and management of acute coronary syndromes among adult persons with haemophilia: results of an international, retrospective, 10-year survey," Haemophilia, vol. 21, no. 5, pp. 589597, 2015.

[10] S. Okada, T. Morimoto, H. Ogawa et al., "Is long-term low-dose aspirin therapy associated with renal dysfunction in patients with type 2 diabetes? JPAD2 cohort study," PLoS ONE, vol. 11, no. 1, Article ID e0147635, 2016.

[11] T.-C. Hsieh, S.-T. Wu, D. J. Bennett, B. B. Doonan, E. Wu, and J. M. Wu, "Functional/activity network (FAN) analysis of gene-phenotype connectivity liaised by grape polyphenol resveratrol," Oncotarget, vol. 7, no. 25, pp. 38670-38680, 2016.

[12] J.-A. Lin, C.-H. Kuo, B.-Y. Chen et al., "A novel enzyme-assisted ultrasonic approach for highly efficient extraction of resveratrol from Polygonum cuspidatum," Ultrasonics Sonochemistry, vol. 32, pp. 258-264, 2016.

[13] J. A. Shin, H. Lee, Y.-K. Lim, Y. Koh, J. H. Choi, and E.-M. Park, "Therapeutic effects of resveratrol during acute periods following experimental ischemic stroke," Journal of Neuroimmunology, vol. 227, no. 1-2, pp. 93-100, 2010.

[14] N. O. Solberg, R. Chamberlin, J. R. Vigil et al., "Optical and SPION-Enhanced MR imaging shows that trans-stilbene inhibitors of NF- $\kappa \mathrm{B}$ concomitantly lower alzheimer's disease plaque formation and microglial activation in $\mathrm{A} \beta \mathrm{PP} / \mathrm{PS}-1$ transgenic mouse brain," Journal of Alzheimer's Disease, vol. 40, no. 1, pp. 191-212, 2014.

[15] Z. Meng, J. Li, H. Zhao et al., "Resveratrol relieves ischemiainduced oxidative stress in the hippocampus by activating SIRT1," Experimental and Therapeutic Medicine, vol. 10, no. 2, pp. 525-530, 2015.

[16] X. Feng, N. Liang, D. Zhu et al., "Resveratrol inhibits $\beta$ amyloid-induced neuronal apoptosis through regulation of SIRT1-ROCK1 signaling pathway," PLoS ONE, vol. 8, no. 3, Article ID e59888, 2013.

[17] R. Takahashi and A. Yoshimura, "SOCS1 and regulation of regulatory T cells plasticity," Journal of Immunology Research, vol. 2014, Article ID 943149, 8 pages, 2014.

[18] J. Kim, I. Jou, and E. Joe, "Suppression of miR-155 expression in IFN- $\gamma$-treated astrocytes and microglia by DJ-1: a possible mechanism for maintaining SOCS1 expression," Experimental Neurobiology, vol. 23, no. 2, pp. 148-154, 2014.

[19] X. Liu, J. Li, X. Peng et al., "Geraniin inhibits LPS-induced THP1 macrophages switching to M1 phenotype via SOCS1/NF- $\kappa \mathrm{B}$ pathway," Inflammation, vol. 39, no. 4, pp. 1421-1433, 2016.
[20] H. Cai, Q. Liang, and G. Ge, “Gypenoside attenuates $\beta$ amyloidinduced inflammation in N9 microglial cells via SOCS1 signaling," Neural Plasticity, vol. 2016, Article ID 6362707, 10 pages, 2016.

[21] L. Ma, J. Jia, X. Liu, F. Bai, Q. Wang, and L. Xiong, "Activation of murine microglial N9 cells is attenuated through cannabinoid receptor CB2 signaling," Biochemical and Biophysical Research Communications, vol. 458, no. 1, pp. 92-97, 2015.

[22] G. Bénard, F. Massa, N. Puente et al., "Mitochondrial $\mathrm{CB}_{1}$ receptors regulate neuronal energy metabolism," Nature Neuroscience, vol. 15, no. 4, pp. 558-564, 2012.

[23] L. J. Simmons, M. C. Surles-Zeigler, Y. Li, G. D. Ford, G. D. Newman, and B. D. Ford, "Regulation of inflammatory responses by neuregulin-1 in brain ischemia and microglial cells in vitro involves the NF-kappa B pathway," Journal of Neuroinflammation, vol. 13, no. 1, article no. 237, 2016.

[24] S. D. Rege, T. Geetha, G. D. Griffin, T. L. Broderick, and J. R. Babu, "Neuroprotective effects of resveratrol in Alzheimer disease pathology," Frontiers in Aging Neuroscience, vol. 6, article 218,2014

[25] M. Maepa, M. Razwinani, and S. Motaung, "Effects of resveratrol on collagen type II protein in the superficial and middle zone chondrocytes of porcine articular cartilage," Journal of Ethnopharmacology, vol. 178, pp. 25-33, 2016.

[26] G. J. Soleas, E. P. Diamandis, and D. M. Goldberg, "Wine as a biological fluid: history, production, and role in disease prevention," Journal of Clinical Laboratory Analysis, vol. 11, no. 5, pp. 287-313, 1997.

[27] R.-S. Chen, P.-L. Wu, and R. Y.-Y. Chiou, "Peanut roots as a source of resveratrol," Journal of Agricultural and Food Chemistry, vol. 50, no. 6, pp. 1665-1667, 2002.

[28] M. Zhu, Q. Zhang, X. Wang et al., "Metformin potentiates anti-tumor effect of resveratrol on pancreatic cancer by downregulation of VEGF-B signaling pathway," Oncotarget, vol. 7, no. 51, pp. 84190-84200, 2016.

[29] D. Xu, Y. Li, B. Zhang et al., "Resveratrol alleviate hypoxic pulmonary hypertension via anti-inflammation and anti-oxidant pathways in rats," International Journal of Medical Sciences, vol. 13, no. 12, pp. 942-954, 2016.

[30] H. Huang, G. Chen, D. Liao, Y. Zhu, R. Pu, and X. Xue, “The effects of resveratrol intervention on risk markers of cardiovascular health in overweight and obese subjects: a pooled analysis of randomized controlled trials," Obesity Reviews, vol. 17, no. 12, pp. 1329-1340, 2016.

[31] N. Latruffe and J.-P. Rifler, "Bioactive polyphenols from grapes and wine emphasized with resveratrol," Current Pharmaceutical Design, vol. 19, no. 34, pp. 6053-6063, 2013.

[32] K. Nosho, K. Shima, N. Irahara et al., "SIRT1 histone deacetylase expression is associated with microsatellite instability and CpG island methylator phenotype in colorectal cancer," Modern Pathology, vol. 22, no. 7, pp. 922-932, 2009.

[33] M. Masuhara, H. Sakamoto, A. Matsumoto et al., "Cloning and characterization of novel CIS family genes," Biochemical and Biophysical Research Communications, vol. 239, no. 2, pp. 439446, 1997.

[34] J. Piessevaux, D. Lavens, F. Peelman, and J. Tavernier, "The many faces of the SOCS box," Cytokine \& Growth Factor Reviews, vol. 19, no. 5-6, pp. 371-381, 2008.

[35] R. Starr and D. J. Hilton, "SOCS: suppressors of cytokine signalling," The International Journal of Biochemistry \& Cell Biology, vol. 30, no. 10, pp. 1081-1085, 1998. 
[36] K. Łabuzek, D. Suchy, B. Gabryel, O. Pierzchała, and B. Okopień, "Role of the SOCS in monocytes/macrophages-related pathologies. Are we getting closer to a new pharmacological target?" Pharmacological Reports, vol. 64, no. 5, pp. 1038-1054, 2012.

[37] T. Dragone, A. Cianciulli, R. Calvello, C. Porro, T. Trotta, and M. A. Panaro, "Resveratrol counteracts lipopolysaccharidemediated microglial inflammation by modulating a SOCS-1 dependent signaling pathway," Toxicology In Vitro, vol. 28, no. 6, pp. 1126-1135, 2014.

[38] D. D. Lofrumento, G. Nicolardi, A. Cianciulli et al., "Neuroprotective effects of resveratrol in an MPTP mouse model of Parkinson's-like disease: possible role of SOCS-1 in reducing pro-inflammatory responses," Innate Immunity, vol. 20, no. 3, pp. 249-260, 2014.

[39] C. Ma, Y. Wang, A. Shen, and W. Cai, "Resveratrol upregulates SOCS1 production by lipopolysaccharide-stimulated RAW264.7 macrophages by inhibiting miR-155," International Journal of Molecular Medicine, 2016. 


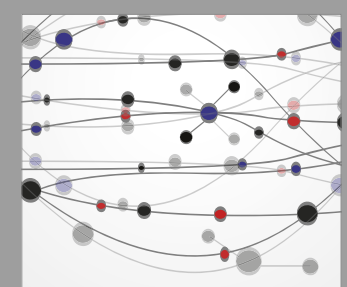

The Scientific World Journal
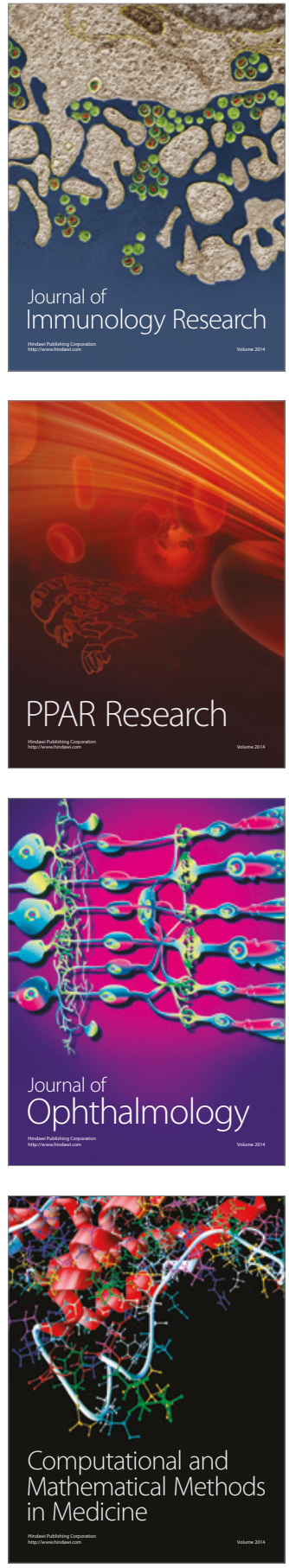

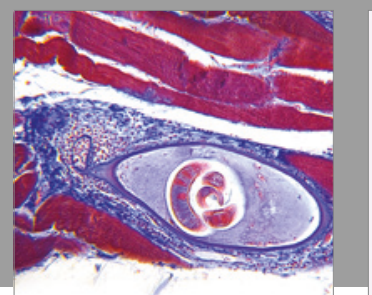

Gastroenterology Research and Practice
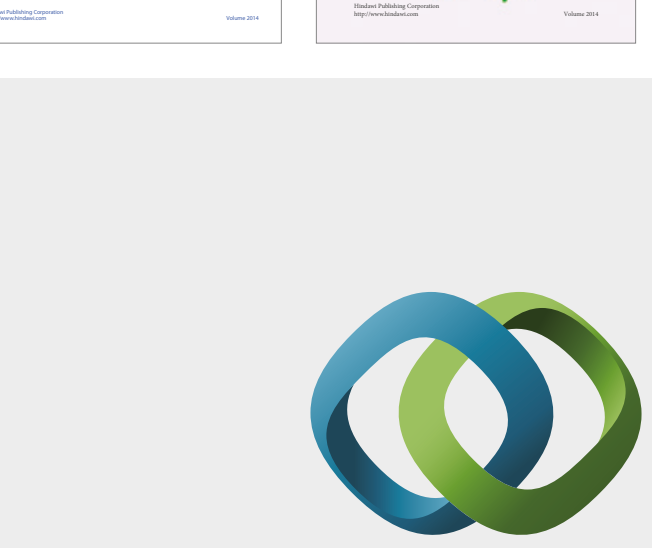

\section{Hindawi}

Submit your manuscripts at

https://www.hindawi.com
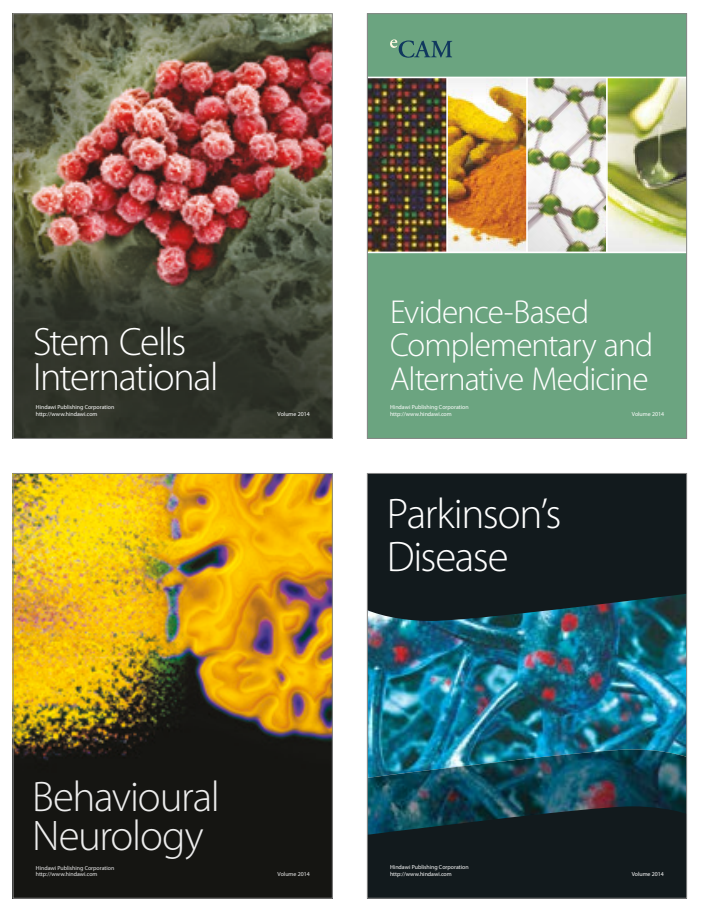
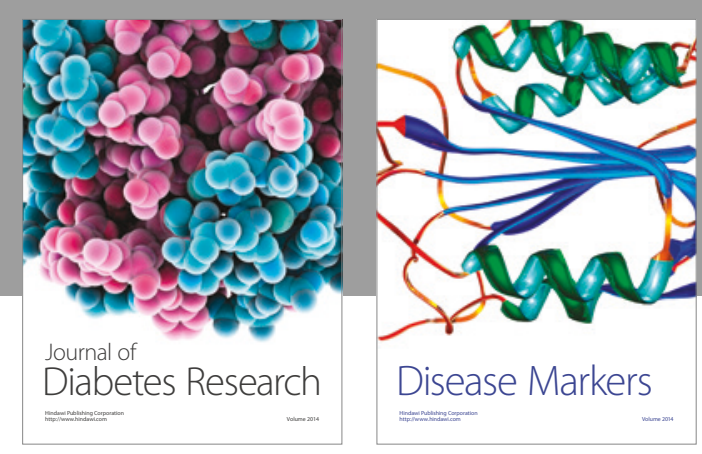

Disease Markers
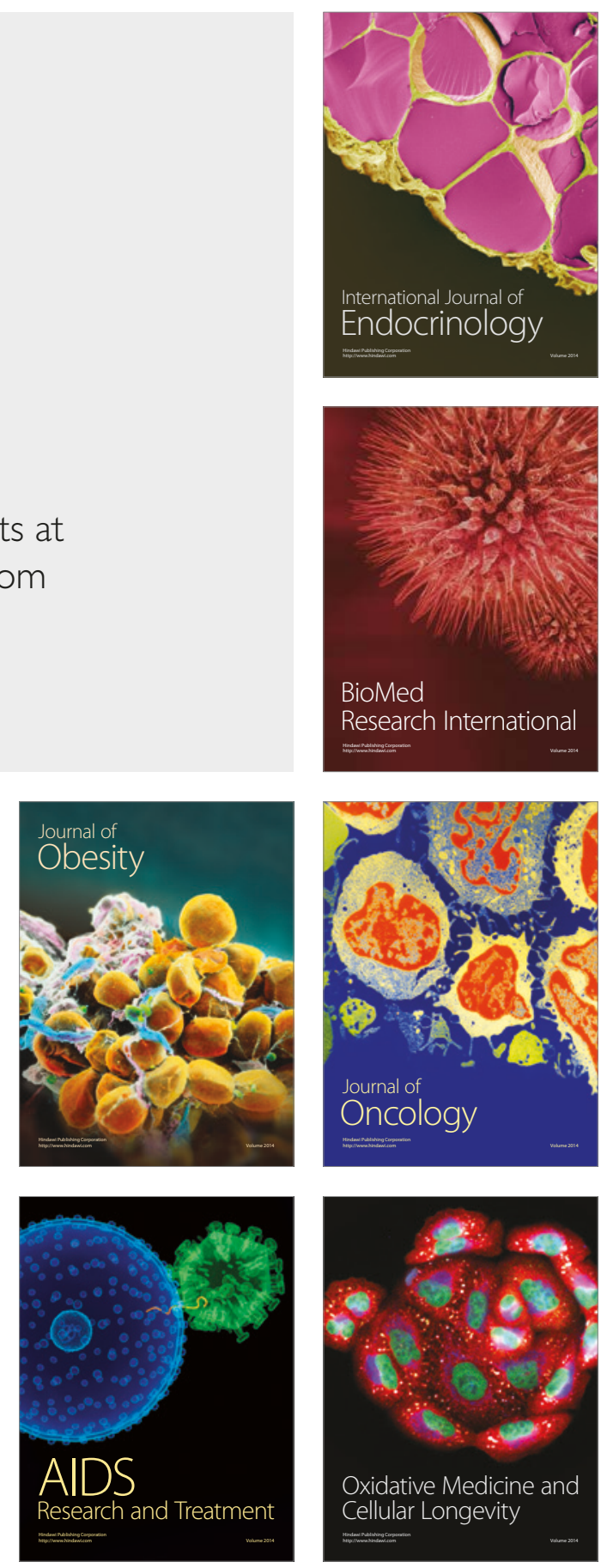